DOI: $10.35643 /$ Info.26.2.5

Dossier temático: Biblioterapia

\title{
Al encuentro de la palabra: consideraciones para las prácticas de promoción de lectura en la escuela como escenario para la memoria y la ética
}

\author{
Meeting with the word: Considerations for reading \\ promotion practices in school as a setting for memory and \\ ethic
}

\section{Encontrando a Palavra: Considerações sobre as Práticas de Promoção da Leitura na Escola como Cenário de Memória e Ética}

Paola Isabel Roa ${ }^{1}$ ORCID: $\underline{0000-0002-4714-6889}$
Silvia Castrillón ${ }^{2}$ ORCID: $\underline{0000-0003-0141-614 X}$

${ }^{1}$ Biblioteca Nacional de Colombia, Colombia. Correo electrónico: paolaisabelroa@gmail.com

${ }^{2}$ Asociación Colombiana de Literatura Infantil y Juvenil (ACLIJ), Colombia. Correo electrónico: silvia.castrillon@gmail.com

\section{Resumen}

Este artículo propone una reflexión sobre las prácticas de promoción de lectura y escritura como mediaciones pedagógicas y culturales importantes dentro de los procesos de recuperación emocional y elaboración de experiencias en niños, niñas y jóvenes víctimas de situaciones de violencia, como el desplazamiento, el abandono, el reclutamiento forzado, la extrema pobreza, el maltrato intrafamiliar, entre otras. Con el sentido ético y la memoria a modo de focos conceptuales, nos aproximamos a las experiencias de lectura de niños, niñas y jóvenes con el fin de dar cuenta de las posibilidades que abre la palabra para el encuentro y el reconocimiento de sí mismos, de los otros y del mundo.

Palabras clave: PROMOCIÓN DE LECTURA Y ESCRITURA; ÉTICA; MEMORIA; MEDIACIONES PEDAGÓGICAS Y CULTURALES. 


\begin{abstract}
This article proposes a reflection on the practices of reading and writing as important pedagogical and cultural mediations within the processes of emotional recovery and elaboration of experiences in children and young people who are victims of violence, such as displacement, abandonment, forced recruitment, extreme poverty, domestic abuse, etc. With the ethical sense and memory as conceptual focuses, we approach the reading experiences of children and young people to give an account of the possibilities that the word opens for the encounter and recognition of themselves, others and the world.
\end{abstract}

Keywords: PROMOTION OF READING AND WRITING; ETHIC; MEMORY; PEDAGOGICAL AND CULTURAL MEDIATIONS.

\title{
Resumo
}

Este artigo propõe uma reflexão sobre as práticas de promoção da leitura e da escrita como importantes mediações pedagógicas e culturais nos processos de recuperação emocional e de elaboração de experiências em crianças e jovens vítimas de situações de violência, como deslocamento, abandono, recrutamento forçado , extrema pobreza, violência doméstica, entre outros. Com o sentido ético e a memória como focos conceituais, abordamos as experiências de leitura de crianças e jovens para dar conta das possibilidades que a palavra abre para o encontro e o reconhecimento de si, dos outros e do mundo.

Palavras chave: PROMOÇÃO DA LEITURA E DA ESCRITA; ÉTICA; MEMÓRIA; MEDIAÇÕES PEDAGÓGICAS E CULTURAIS.

Fecha de recibido: $31 / 05 / 2021$

Fecha de aceptado: 07/09/2021

\section{Introducción}

Durante los años 2008 y 2009, Asolectura (Asociación Colombiana de Lectura y Escritura) desarrolló la propuesta «Grupos de lectura con niños, niñas y jóvenes víctimas de la violencia en Colombia», con el apoyo del Fondo de IBBY para Niños en Crisis. Esta propuesta pretendía - a partir de la creación de grupos de lectura en voz alta, su acompañamiento y observación permanente- desarrollar un componente de formación para maestros sobre la manera en que las prácticas de lectura y escritura y las prácticas para su promoción constituyen herramientas importantes dentro de los procesos de recuperación emocional y elaboración de experiencias en niños, niñas y jóvenes víctimas de situaciones de violencia, como 
el desplazamiento, el abandono, el reclutamiento forzado, la extrema pobreza, el maltrato intrafamiliar, entre otras.

El sentido ético y la memoria fueron los focos conceptuales desde los que se abordó la reflexión sobre la necesidad del acceso a prácticas de lectura y escritura; a la vez, estas categorías orientaron el trabajo en los diferentes grupos de lectura en voz alta y en los seminarios con maestros realizados a lo largo de un año y medio.

El interés por involucrar en forma directa estos aspectos en la construcción de conocimiento sobre la lectura y la escritura y su promoción parte de la necesidad que identificamos de transformar las representaciones que sobre las prácticas de promoción de lectura y escritura tiene la sociedad. Estas prácticas se asocian de manera permanente con fines recreativos o lúdicos, o se limitan al desarrollo de habilidades para la decodificación y reproducción de textos escritos.

En el diseño y el desarrollo del proyecto nos preocupó siempre la forma en que era posible consolidar una práctica de promoción de lectura dentro de diferentes poblaciones, no como alternativa para la diversión y el uso del tiempo libre, sino desde la necesidad. Es decir, nuestro propósito radicaba en articular las prácticas de lectura y escritura con aquellas necesidades de los órdenes simbólico, político, educativo y emocional que configuran la identidad de las personas y que se revierten en sus interacciones con otros. Además, el contexto de violencia colombiano demanda, a nuestra manera de ver, que las organizaciones que se ocupan de los niños y las niñas en proceso de formación - tanto del sector público como del privado, regulares o no- propongan caminos plurales e igualitarios e incorporen a su trabajo fines asociados a una verdadera formación ética, ciudadana y política.

Los grupos de lectura se desarrollaron con poblaciones de niños, niñas y jóvenes de las siguientes instituciones: Fundación San Antonio -Programa Redes: Escuelas para el Tiempo Libre-; Alta Consejería para la Presidencia de la República; Secretaría de Integración Social -Plan de Atención Integral para Población Habitante de Calle-; Idipron (Instituto Distrital para la Protección de la Niñez y la Juventud); Casa del Menor Trabajador; Secretaría de Gobierno —Unidades de Atención para Población Desplazada-; Fundación Funicaf (Fundación Infantil Caminos de Amor y Fe). 


\section{Preliminar. Marco teórico}

Nos reconocemos en nuestras historias. Es gracias a las palabras y a la capacidad de narrar lo que nos sucede que podemos hacernos a una idea de quiénes somos, y es en el acto de la escucha atenta de historias diferentes a la propia como se posibilita el descubrimiento de los otros y de lo otro. Narrando y dejando que nos narren - pero sobre todo deteniéndonos para trascender e interpretar los fragmentos de esas narraciones de las que somos espectadores- nos vamos haciendo a palabras, a imágenes, a recuerdos, a sensaciones con los que podemos construir un lugar desde el cual enunciar, comprender y transformar el mundo; un lugar propio y distinto a cualquier otro, pero compartido con otros. Un lugar en el que resuenan las voces que narran; un lugar habitado por lo que somos, que se ensancha o se agota de acuerdo con las palabras, las imágenes, los recuerdos, las sensaciones, los juicios y la belleza que pongamos, o no, en movimiento. Un lugar desde el cual observar el mundo, para decir de él, para tejer la memoria, para acoger nuestras experiencias y para acoger a los otros; en resumen, ese lugar de lo ético en nuestra existencia.

Es acerca de estas cuestiones que queremos hablar en este documento: sobre la manera como la lectura, la escritura y su promoción enriquecen -al estar fundamentadas en la palabra- las condiciones que hacen posible la construcción de ese espacio desde el que los seres humanos construyen su memoria y su sentido ético; y sobre la necesidad de que para estos fines la escuela asuma de forma más decidida la responsabilidad de poner a las niñas, los niños y los jóvenes en contacto con materiales simbólicos que alimenten sus imaginarios, su lenguaje, su capacidad de expresión y su sentido crítico. Se trata, entonces, de proponer una reflexión sobre el acceso a la cultura escrita, la literatura y el goce estético como mecanismos sólidos y plurales que alimentan la forma en que los niños y las niñas hacen frente a la realidad y construyen sus entornos vitales. Con esto, las prácticas de promoción de lectura sobre las que nos proponemos hablar distan mucho de las concepciones que las sitúan en procesos instruccionales o recreativos, sin posicionamientos reflexivos ni críticos frente a lo que se lee y se escribe.

La siguiente es una apuesta por: 
la lectura y la escritura como medios para el rescate y la revalorización de la palabra en todas sus manifestaciones orales y escritas en un mundo en el que la palabra, la voz y la experiencia están cada vez más relegadas a fines netamente instrumentales para la transmisión de información (Asolectura, 2007).

Nadine Gordimer expresa:

Tener la palabra ha llegado a ser sinónimo de máxima autoridad, de prestigio, de dominio, a veces de persuasión peligrosa o mayor audiencia en televisión, de procurar una grata charla o de hablar varias lenguas. La palabra vuela a través del espacio, rebota entre los satélites, ahora está más cerca del cielo de lo que ha estado nunca (2004)

Así, con esta gigantesca brecha entre la palabra y el ser del hombre, la posibilidad de tránsito entre diferentes realidades y formas de explicar el mundo entre los seres humanos desaparece $\mathrm{y}$, con ella, la idea de una educación para la vida, para la construcción de un sentido vital que permita hablar del aprendizaje desde lógicas diferentes a las de la técnica y las competencias para su uso.

Señalamos en muchas ocasiones la relación entre palabra y educación, o entre lenguaje y educación, asumiendo al lenguaje no solo como el sistema de signos que permite la transmisión de informaciones y la comunicación entre las personas, sino también como la base sobre la cual los seres humanos construyen e interpretan la realidad. Es más, nos acogemos aquí a las nociones que conciben el lenguaje como la forma de la realidad misma.

«El contenido de la vida está en el lenguaje de la vida» (Mate, 2003, p. 57), de tal manera que la educación -en cuanto ejercicio para conocer y explorar los lenguajes con los cuales los seres humanos han explicado el mundo y sus fenómenos- no se encuentra solo al servicio del acceso al conocimiento científico y positivo que ha construido la humanidad, sino que también tiene que ver -en primera instancia desde una perspectiva ética - con el lenguaje como expresión del devenir de la vida, como la manifestación de la experiencia que significa ser receptor de la realidad, de la concreta y convencional y, a la vez, de la realidad de eso que no está disponible siempre para ser dicho y nombrado ni para ser objeto del conocimiento, sino que se presenta como una realidad sujeta a la experiencia de cada ser humano.

Toda praxis pedagógica tiene la función de dotar al recién llegado de un aparato simbólico con el que pueda hacer frente a lo «indisponible» de la existencia humana, a todas aquellas cuestiones imposibles de eludir que 
nunca pueden responderse técnicamente: el dolor, la muerte, el mal, el sentido de la vida... es decir, la (Mèlich, 2002).

En esta lógica del sentido ético es necesario plantear también que esta realidad y este sentido de la vida construidos en el lenguaje no son en ninguna medida procesos que los individuos alimentan en soledad para después vincularlos o sumarlos a los de otros individuos — teniendo como resultado la construcción de sociedad-, sino que es gracias a la interacción con otros como se erige el sentido primero de ser humano; es en el encuentro y en la receptividad de lo desconocido, de lo otro, que el yo adquiere sentido. Gracias a la mirada y a la escucha que los otros nos otorgan nos constituimos en sujetos humanos, se dotan de sentido nuestra acción y nuestra capacidad de nombrar el mundo para decir de él, para escuchar e interpretar la experiencia de los otros y así establecer redes de sentido social que enmarquen y nutran nuestros intercambios.

Si lo «ético» es fundante, es porque nos constituimos a nosotros mismos a partir del otro. Antes de la presencia interpelante del otro somos, sí, pero pura existencia, sueño prolongado. El otro es el que nos saca de nuestro autismo y nos convierte en seres vivos. No somos seres vivos antes de que el otro interrumpa el sueño de nuestra existencia vacía (Mate, 2003, p. 53).

En lo referente a la memoria, la presente propuesta y la práctica de la que partió buscan constituirse en una contribución para fundamentar el trabajo sobre la reconstrucción de memoria desde el escenario pedagógico. Para ello, la reflexión y el trabajo estuvieron ubicados también en los terrenos del lenguaje, de la imaginación y de lo simbólico, con el aporte definitivo de la literatura, en la medida en que no se asumió la memoria como un mecanismo para la acumulación de información o como medio para acceder al pasado a través del recuerdo, sino como un proceso de intercambio entre los seres humanos de sus narraciones del pasado, de sus interpretaciones y de sus reflexiones sobre el presente y el futuro en permanente retroalimentación.

En el diseño de las acciones del proyecto y de los componentes de formación de maestros nos referimos a la memoria, a hacer memoria, como un diálogo siempre abierto al que todos los seres humanos -los vivos, los muertos, los silenciosos, los atemorizados, las víctimas y los victimarios- deben tener acceso para construir el sentido de lo que fue, de lo que es y de lo que será, con un alto grado de responsabilidad y con poder dilucidador frente a los discursos homogéneos y 
autoritarios — tanto privados como públicos-, que fijan versiones de los hechos ocurridos y a su vez establecen derroteros para pensar el presente.

Nos interesa pensar la relación entre educación, memoria y ética a través de la movilización del lenguaje simbólico por medio de la lectura y la escritura. Por un lado, porque identificamos -durante el proceso de exploración y acercamiento a las instituciones encargadas de prestar atención a las poblaciones en situación de vulnerabilidad y en los espacios de conversación y formación con maestros- que son muy pocos los escenarios en los que sentir, argumentar, escuchar y leer tienen cabida, pues, por el contrario, se privilegian las relaciones unidireccionales para la transmisión de información, el aprendizaje técnico y el asistencialismo terapéutico intrascendente. Por otro lado, porque consideramos que es en este replegarse silencioso de la palabra y del mundo simbólico que la escuela, las instituciones culturales y buena parte de la sociedad se convencen de que solo con los conocimientos de tipo instrumental y técnico los niños, las niñas y los jóvenes podrán hacer frente a las demandas de la vida actual y al futuro.

Habría que tener en cuenta que en un país como Colombia el futuro depende, en gran medida, de un orden de cosas que tiene que ver con la vida, con su conservación, con la imperiosa necesidad de que ningún otro niño, niña o joven devenga en victimario, y con el establecimiento de procesos de memoria que hagan posible - a partir del diálogo y el intercambio de lo que significa para cada uno estar vivo- reconocernos entre quienes compartimos el presente para forjar una responsabilidad con aquellos que han sido víctimas y que se relegan a un pasado que se entiende como lugar para el olvido.

\section{La autosuficiencia de la autonomía}

La necesidad de abrir una discusión alrededor de la lectura y la escritura como trabajos para la memoria y la ética en la escuela surge de una preocupación sobre la forma en la que el concepto de autonomía y subjetividad se está apoderando del discurso escolar contemporáneo vinculando dichas categorías, por un lado, a la demanda de seres competitivos que sepan desempeñarse dentro de un mundo globalizado - para quienes, dentro de la lógica de las desigualdades sociales, las posibilidades de garantizar una calidad de vida dependen de las destrezas laborales e intelectuales con las que puedan competir con otros en la búsqueda del 
éxito-, y, por otro lado, a la movilización del culto al yo, a la individualidad y al interés personal como verdad y punto de partida para la comprensión de todo lo que acontece.

Se trata de una comprensión que se reduce a entender lo que está delante de sí a partir de significados ya dados e inmóviles que refuerzan la comodidad consigo mismo; o, en el caso de la sociedad de masas, de un culto al yo determinado por una autocontemplación que, a la par que reduce todo a lo conocido y explicado por la colectividad, uniforma a los individuos. Incluso en aquellos casos en los que los jóvenes pretenden distinguirse mediante acciones contestatarias sus alternativas también son determinadas y capitalizadas por la sociedad dominante mediante las industrias culturales, que los conduce otra vez a tendencias gregarias que reducen las posibilidades de miradas críticas y plurales sobre la realidad.

La desaparición del individuo consiste en que los seres humanos están dejando de ser únicos e irremplazables, válidos por sí mismos, para convertirse en seres cada vez más parecidos entre ellos y más anónimos, cuyas actividades, comportamiento y pensamiento están moldeados socialmente para servir a los intereses del todo social. Durante las horas de trabajo son trabajadores, y en sus ratos de ocio consumidores de las distracciones que la sociedad les impone. Si alguien busca todavía experiencias más libres, las agencias de turismo le gestionan salidas a la naturaleza; si uno pretende huir a la contracultura o la vida bohemia, el departamento de cultura pone a su disposición cursos introductorios. Todas las esferas de la vida caen bajo la administración social y no hay donde escapar (Tafalla, 2003).

La autonomía y la subjetividad que se pretenden en la actualidad (cuyo discurso está siendo reproducido en gran medida por la escuela y los planes de educación del Estado) resultan ser criterios que se alimentan para legitimar la interacción entre las personas solo a través de su individualidad y competitividad y mediante los intercambios productivos para fines útiles inmediatos. Se fomentan tipos de relaciones en las que se desconocen elementos esenciales de la vida en comunidad y de la capacidad de experiencia común para transformarse mutuamente; relaciones en las que la ética se subordina a tolerar al otro, siempre y cuando se mantenga a distancia. Oportuno resulta citar lo que señala Alain Badiou (2004):

En verdad, este famoso «otro» es presentable únicamente si es un buen otro; es decir, ¿qué otra cosa sino el mismo que nosotros mismos? ¡Respeto a las diferencias, claro que sí! Pero a reserva de que el diferente sea demócrata parlamentario, partidario de la economía de mercado, sostén de la libertad de opinión, feminista, ecologista... Lo que también puede decirse así: yo 
respeto las diferencias, en la medida en que quien difiere de mí respete exactamente como yo dichas diferencias.

Se subestiman los escenarios en los que la expresión de la subjetividad no es el éxito y el avance a codazos con respecto a los demás, sino la forma como se pone en diálogo la diferencia constitutiva de cada ser con una pluralidad[1] en la que discurren múltiples miradas del mundo, diferentes mecanismos para comprender lo que ocurre en lo cotidiano. En el caso de esta experiencia, estos escenarios están dados por la lectura en voz alta, la lectura compartida, el diálogo y los diversos encuentros con la palabra y la literatura.

\section{La experiencia}

Buscamos promover en el ámbito escolar y en el de la atención a población vulnerable una reflexión sobre la lectura y la escritura como mediaciones pedagógicas potentes en la educación simbólica y social; prácticas de lectura que al involucrar el mundo simbólico, la imaginación, la narración y la interpelación crítica contribuyan a enriquecer la formación de niños, niñas y jóvenes en lo concerniente a su sentido ético[2].

A partir del trabajo de promoción de lectura con 15 grupos -de los 20 que estaban programados al inicio- de niños, niñas, jóvenes y jóvenes adultos en situación de desplazamiento, extrema pobreza o desmovilización de los grupos armados, se adelantó una observación cualitativa de la que son producto el presente documento, la propuesta de criterios para la selección de repertorios de lectura Pluralidad, literatura y mediación, y un informe detallado del proceso de trabajo con estas poblaciones. Así mismo, fue fundamental el trabajo realizado con cerca de doscientos maestros y maestras del sector público de Bogotá y de otras regiones del país mediante seminarios de formación en los que se pusieron en discusión los criterios abordados en la presente propuesta. Estos seminarios se constituyeron también en escenarios en los que se dio inicio a la divulgación y reflexión de las cuestiones aquí planteadas.

También fueron insumos para este trabajo las observaciones y reflexiones originadas en los Clubes de Lectores - promovidos por Asolectura junto con la Secretaría de Cultura, Recreación y Deporte-, el programa Escritores a la Escuela - realizado por Asolectura para la Secretaría de Educación en el año 
2007- y Argos Construye Lectores, programa apoyado por la Fundación Argos que tuvo lugar durante 2009.

\section{La ética y la memoria como punto de partida y}

\section{retorno}

El hecho de que las prácticas de lectura y escritura en la escuela y los espacios culturales tengan implicaciones en la formación del sentido ético de niños, niñas y jóvenes requiere, por un lado, de la reflexión para la transformación y el enriquecimiento de la concepción predominante que tenemos de la ética —un supuesto convencional y rígido desde el que se pauta el deber ser de conductas, valores y emociones- y, por otro, de la adopción, como consecuencia de la transformación de dicha concepción, de una postura frente a la ética que la sitúe en lo cotidiano -en el cotidiano encuentro de los humanos con los humanos-, que lo trascienda y asuma esa postura como una noción viva y móvil en la que nuestro actuar se configura en estrecho vínculo con los otros y con el proyecto común en el que nos jugamos una vida digna. Es decir, un horizonte de significación en el que, a diferencia de los decálogos con los que se acostumbra juzgar y justificar los comportamientos, se enmarquen las condiciones para el intercambio de las diferencias, para el encuentro de sí mismo con la particularidad del otro.

En las diferentes fases de trabajo con maestros y mediadores de lectura, en especial en los seminarios y las observaciones de prácticas de promoción de lectura, identificamos que la referencia directa que se establece entre la lectura y la ética es la que tiene relación con la moraleja, la prédica y la fijación del sentido de lo que es leído por el adulto.

En esta dirección, las obras literarias y los materiales de lectura son evaluados por los maestros desde categorías del orden de los valores y con expectativas que privilegian las moralejas y las enseñanzas explícitas. Se da poca cabida a argumentos complejos y a historias que problematicen la realidad y los órdenes establecidos. Se censuran temas relacionados con la sexualidad, la violencia, la emancipación de las comunidades y su reivindicación del destino propio, y la explicación de los conflictos sociales y políticos del país. Es sobresaliente la tendencia a neutralizar las opiniones que despierta un texto. Se busca en la mayoría de los casos finalizar una sesión de lectura en voz alta u otra actividad de 
lectura haciendo conclusiones generales y uniformes que delimitan la interpretación y que no invitan a la conversación para la construcción conjunta de sentido.

Nos propusimos, a partir de la identificación y la socialización de estas tendencias, promover en comunidades de maestros una discusión sobre diferentes obras de literatura y prácticas de promoción de lectura en las que los significados de los textos y el contenido de las conversaciones propiciaran experiencias para el reconocimiento y la observación de la complejidad humana en diálogo con la realidad de sus comunidades y de nuestro país.

Tal fue el caso de los seminarios realizados sobre nueve obras de literatura infantil colombiana - «Literatura infantil y juvenil: nueve historias colombianas, nueve miradas a una misma realidad»—, en los que se retrataron situaciones y experiencias de niños, niñas y jóvenes en el conflicto armado o la vulnerabilidad social.

En los seminarios se buscó explorar junto con los maestros la manera en que esta literatura podía contribuir a la construcción de sentido sobre asuntos que afectan la vida cotidiana de gran parte de niños, niñas y jóvenes colombianos. Partiendo de la lectura en voz alta de fragmentos de las obras y de textos teóricos para luego ampliar el espectro de discusión, reflexionamos y conversamos con los maestros y mediadores sobre el sentido que tenían dichas problemáticas en sus vidas y compartimos relatos sobre las experiencias de diferentes estudiantes que asisten a la escuela, cuyas realidades a menudo son difíciles de exteriorizar, tanto para ellos como para sus familias y sus profesores.

La perspectiva ética de esta propuesta de mediación de lectura y escritura se manifiesta en el desarrollo de las conversaciones entre lectores y textos. En función de una reflexión que trasciende lo individual y se propone enunciar, comprender y hacer memoria, se consigue poner en el centro del encuentro la experiencia de personas cuyas vivencias del mundo y de los conflictos humanos tienen que ser escuchadas y acogidas desde una mirada ética —empática- para participar de la construcción de sentido del mundo y la realidad. Así, la lectura y la escritura se asumen como mediaciones éticas para la afirmación de la vida y el intercambio de experiencias y pensamiento. 


\section{La ética y la atención a poblaciones vulnerables}

En Colombia, por ejemplo, al hablar de ética habría que cuidarse de no dogmatizar los discursos, de no hacer de cuestiones como el desplazamiento, la violencia y el reclutamiento etiquetas vacías que solo designan una realidad corporal[3]. Hasta ahora se hace evidente que la atención a las personas en situaciones de crisis se limita a buscar sin orden un bienestar en los planos material y corporal, lo que por regla general deriva en asistencialismos y altruismos insustanciales que no permiten trascender la realidad vital de las víctimas, marcada por la barbarie. No nos convoca a la responsabilidad de escuchar la voz que habita el cuerpo de la víctima. Solo la escuchamos a través de los índices convencionales a los que la reducimos en su victimización (la pobreza, el hambre, la suciedad, el desamparo), no como sujeto dotado de pensamiento y actuar propios.

En el proceso adelantado para la incorporación de grupos de lectura y discusión en los programas de atención a poblaciones en situación de desplazamiento y desmovilización -durante el desarrollo de los grupos de lectura con niños y niñas en las unidades para atención integral a poblaciones desplazadas-, con frecuencia pudimos observar cómo, dentro del protocolo oficial para la atención a las víctimas del desplazamiento, la palabra de estas personas solo tiene valor en la medida en que dé cuenta de actos violentos, es decir, en la medida en que sus relatos sirvan como testimonios dentro del contexto de la indagatoria, la burocracia judicial o el efectismo mediático.

Con el reconocimiento del problema y el interés en transformar esta tendencia, avanzaríamos, como plantea Alain Badiou (2004), de la piedad a la justicia. Una política justa es la consecuencia de dos afirmaciones: todo cuerpo soporta un pensamiento; todo el mundo es igual a todo el mundo.

Badiou expresa:

¿Podemos fundar una idea de la justicia a partir del cuerpo como espectáculo? Yo creo que hay que responder negativamente, ciertamente la piedad es un sentimiento importante, pero podemos ir directamente de la piedad a la justicia, porque para ir a la justicia, se hace necesario algo más que el cuerpo sufriente, se hace necesario una definición de la humanidad, más amplia que la víctima, es necesario que la víctima sea testimonio de algo más que la víctima (2004). 
Así mismo, Badiou agrega que la víctima es cuerpo creador, cuerpo que porta ideas y está dotado de pensamiento.

Resumiendo, de lo que se trata es de pensar a las víctimas, entre ellas a las personas en situación de vulnerabilidad, más allá de los hechos tangibles que las determinan como tales (la muerte, la violencia, el hambre, el abandono), para que las atenciones a su situación no sean solo de carácter material e inmediato. Se pretende, mediante prácticas pedagógicas y culturales, orientar acciones para conseguir, por un lado, la movilización social de una reflexión profunda que tenga como resultado reconocer a las víctimas y los condicionamientos de su situación $\mathrm{y}$, por otro lado, condiciones pedagógicas, culturales y políticas para que las víctimas puedan expresar su palabra y las ideas que porta su cuerpo vulnerado en su condición de ser humano que piensa, siente, habla, sueña, juzga.

Conseguir el propósito de este objetivo se dificulta en la medida en que, por lo general, las víctimas, en sus contextos naturales, también han sido excluidas del uso de la palabra e imposibilitadas para la transmisión de experiencias.

En el caso de los grupos con población desmovilizada, no bastaba con la apertura de los espacios para la lectura en voz alta. Sus participantes se caracterizaban por expresiones de interés muy parcas, por el casi nulo uso de la palabra en público y, sobre todo, por la extrañeza o el rechazo a incorporar elementos de carácter emotivo o metafórico en su comunicación con otros. Así mismo, el acto de escuchar historias representaba una dificultad expresada por ellos en la incomodidad de detenerse en «cosas que no existen» o en expresiones poéticas muy «románticas» sobre la realidad. En estos casos predominaba la burla o la agresividad frente a los relatos y a las intervenciones del mediador.

Para el equipo de trabajo de mediadores fue de mucha ayuda reflexionar y discutir acerca de los posibles motivos que determinan estas actitudes. Uno de ellos fue pensar en el escaso valor que tiene la palabra en los contextos de guerra, en los que, según los participantes de los grupos de lectura, la comunicación con los otros se limita a dar y recibir órdenes, o en los que el diálogo cuenta con tiempos y lugares limitados. Así mismo, en esos contextos la posibilidad de opinar es nula. Los grupos de lectura inauguraban una manera distinta de relacionarse mediante la argumentación, el juicio crítico y la socialización de ideas. 


\section{Leer y escribir: representar el mundo}

Las prácticas de lectura y escritura, en especial aquellas que involucran a la literatura, permiten poner en el terreno de los símbolos los actos más trascendentes de la vida humana $\mathrm{y}$, por lo tanto, enriquecen y dotan de sublimación la transmisión de experiencia y lenguaje mencionados anteriormente. Es la capacidad de simbolizar lo que permite a los hombres compartir la condición humana, de acuerdo con Lluís Duch, «en el fondo, la aptitud simbólica, que es lo que real y radicalmente comparten todos los humanos, es la base más firme e incontestable para la afirmación de la única humanidad del hombre; cursivas añadidas» (2004, p. 28), en la medida en que los símbolos les permiten trascender la realidad a partir de mitos y rituales compartidos, universales y plurales (Roa, P. y Castrillón, S. 2012, pp.180-181).

Al leer, al hacer un trabajo de simbolizar, los intérpretes asocian al signo representaciones e ideas a partir de las cuales es posible nombrar la realidad. Una obra literaria, de esta manera, es un conjunto de símbolos que al momento de ser escritos contienen la carga significativa que el autor impregnó en ellos y que al entrar en contacto con el lector adquieren sentido gracias a que este, a su vez, pone en juego su carga significativa. El lector, gracias al poder evocador de lo simbólico, les presta a las representaciones ideadas por el escritor el sentir que necesitan para adquirir vida, para existir, valorizando así el uso de la palabra y del lenguaje estético como formas de acceso a la humanidad de los otros.

La lectura en voz alta y la discusión de textos nos permitían llevar al escenario público estas representaciones e interpretaciones. Nos proponíamos un ejercicio de construcción compartida de significados. Confrontando el acto de lectura íntima -en la que el diálogo se establece entre la obra y el lector- con la dinámica de los grupos de lectores en la que un tercer actor participa de la lectura, nos percatamos de la manera en que el acto de simbolizar e interpretar el sentido de las historias se ve influido y enriquecido por la conversación. Se comunica el significado propio de una lectura y, mediante el argumento y la persuasión, se van incorporando diferentes miradas sobre los textos y las historias que se narran a partir de ellos. Incluso aquellas personas que no participan de forma explícita acceden a un escenario dialógico de carácter público sobre el que pueden asumir posturas críticas frente a los intercambios discursivos que allí se dan.

Esta posibilidad de visibilización y exteriorización de interpretaciones de la realidad, a partir del código literario, nos despertó interés por rastrear y contrastar 
la diversidad de imaginarios y representaciones que sobre muchos temas tienen las comunidades y los individuos. Por ejemplo, leer libros y procurar una conversación sobre el amor o el viaje en una comunidad de jóvenes habitantes de la calle revela de manera significativa sentidos y formas de nombrar y representar estos fenómenos diferentes a lo que sucedía en una comunidad de jóvenes adultos en proceso de reinserción a la sociedad, o en un grupo de madres solteras entre los 12 y los 16 años, en cuanto al diálogo, la lectura y la socialización de ideas[4]. Aunque con frecuencia los actos de lo simbólico y lo argumentativo en la sociedad se asumen de forma implícita y sobre ellos no hay una reflexión y visibilización cotidianas, las prácticas de promoción de lectura son escenarios siempre y cuando el maestro y el mediador hagan de ellas prácticas reflexionadas y trascendentes- en los que sus participantes sienten que son tomados en serio y que sus argumentos y los significados que le dan a lo que escuchan y perciben tienen valor y efecto sobre las percepciones de los demás.

\section{No se trata de consignas ni recetas}

No se trata de mitificar la lectura ni de pensar que el acto de leer en sí mismo constituye una garantía para mejorar las relaciones entre los seres humanos y para una toma de conciencia ética. Se trata de que la lectura y la literatura formen parte de las posibilidades con las que cuenta la escuela para echar a andar una pedagogía ética que dé lugar a la discusión y contribuya a la formación del juicio crítico sobre la reproducción de desigualdades y violencias que se dan en la escuela. Para decir con Bárcena:

\footnotetext{
No quiero sostener que más lectura y, sobre todo, una lectura mejor, tiene como fin natural arreglar los problemas de la humanidad. (...) Lo que deseo decir es que el fin de la lectura es que el lector deje de leer y mire a quien tiene al lado. (...) Creo que la lectura nos ayuda a entender en qué consiste vivir en un «mundo narrado» repleto de múltiples historias y mitos (Bárcena, 2004, p. 144).
}

Nos interesa resaltar que tanto las representaciones sobre la bondad de la lectura como las prácticas para su promoción demandan un permanente cuestionamiento, con el fin de que no caigan en la rutinización o en la consigna intrascendente. Las prácticas pedagógicas, aun las que se encuentren ya transformadas, tocadas o intervenidas por estas y otras reflexiones, no pueden estancarse en la repetición 
acrítica y aislada de procedimientos. Ello solo es posible si estas representaciones y estas prácticas son sometidas al escrutinio periódico de los maestros y de otras personas relacionadas con la escuela y su entorno que se preocupen por estos problemas.

\section{Sin la memoria jamás podríamos responder a la pregunta ¿quién soy?[5]}

Es el pasado común lo que permite a un individuo saberse perteneciente a un grupo. Un pasado que gracias a la palabra y a mediaciones culturales como la literatura y el arte permanece vivo e interactúa con el presente y el futuro dando movimiento y vitalidad a la interpretación de quienes fuimos, quienes somos y quienes queremos ser.

Según Elizabeth Jelin, en su libro Los trabajos de la memoria (2002), la relación con el tiempo y el sentido de pertenencia a él es el núcleo de cualquier identidad individual o grupal: «Poder recordar y rememorar algo del propio pasado es lo que sostiene la identidad». Señala que este sentido de pertenencia al tiempo y al pasado hace referencia a la memoria:

La memoria es un elemento constitutivo del sentimiento de identidad, tanto individual como colectivo, en la medida en que es un factor extremadamente importante del sentimiento de continuidad y de coherencia de una persona o de un grupo en su reconstrucción de sí mismo (Jelin, 2002).

Durante el desarrollo del proyecto se asumió la memoria como un proceso comunitario continuo y ético por medio del cual es posible reconstruir con una distancia interpretativa las historias de los sujetos, poniendo en diálogo el pasado, el presente y el futuro. Nos interesaba abordar la categoría de la memoria teniendo en cuenta la situación por la que atraviesan Colombia y en particular los niños, las niñas y los jóvenes con quienes nos reuníamos a leer y a conversar. Porque se hace evidente la necesidad de que las personas, en especial las víctimas de diferentes tipos de agresiones, se apropien de sus relatos de vida, tomen distancia crítica de ellos incorporándolos en el lenguaje, dotándolos de sentido y vinculándolos a narraciones y formas universales de sentir y explicar. Se trata, así, de que se puedan elaborar los duelos, y de que las niñas, los niños y los jóvenes al narrar y confrontar sus historias sientan un dominio sobre lo que les acontece, 
reivindicando su libertad y oponiéndose a ser víctimas pasivas de la acción de otros.

La ética, vista desde este foco de continuidad y constitución del sujeto, encuentra una relación de semejanza con la memoria, semejanza que las vincula en retroalimentación. Cuando los sujetos hacen de su memoria una posibilidad de formación, se disponen, a su vez, en el ejercicio reflexivo e interpretativo de lo suyo a una escucha y una comprensión éticas frente a lo que a los otros les pasa. Si la memoria transita a través del pasado, el presente y el futuro para adquirir un significado completo, la ética necesita también hacer este recorrido a través de una mirada en retrospectiva de las relaciones con los otros; necesita de la reflexión constante sobre el intercambio con quienes se comparte la realidad inmediata -el presente- y de la proyección de las relaciones de acogida y confrontación de las diferencias con las que se convive en el futuro. Esto supone, entonces, un ejercicio constante de apertura e integración de la memoria y el sentido propios con los actos de memoria e interpretación que sobre sí hace el otro.

Es una retroalimentación de relatos que, al convertirse en objeto de escucha atenta $y$ al hacernos responsables de la experiencia que narran, permite el entendimiento de aquello que no se puede explicar de manera técnica (las diferencias, el ataque, el sufrimiento) y nos ubica en una posición de responsabilidad respecto de lo que acontece a aquellos con quienes se interactúa. Esto nos convoca a la certeza de que lo que soy afecta la contigüidad de la condición humana y de que mi escucha y mi voz son manifestaciones del acontecer ajeno, incluso de aquellos que ya no están y cuya memoria adquiere vigencia cuando su voz es traída al presente y tenida en cuenta.

Otro de los rasgos sobre los que nos interesaba reflexionar, en lo concerniente a la importancia de la literatura y la obra de arte para la construcción de memoria en función de la ética, tenía que ver con el sentimiento de continuidad y de referencia universal en el que se inscriben los actos individuales. Por tal razón, en los seminarios con los maestros incorporamos como temas de trabajo y reflexión los del arte y la literatura en tanto patrimonio cultural que les permite a los seres humanos reconocerse en culturas que los preceden mediante mitos, creencias e interpretaciones sobre los acontecimientos que siempre han afectado y asombrado al hombre. 
En la obra de arte la humanidad encuentra un vehículo para transmitir a sus futuras generaciones las formas y los lenguajes con los que dieron explicación y sentido a sus experiencias. En ella se plasman las formas particulares con las que se ha ido representando el mundo según el repertorio simbólico de cada época o lugar. En este sentido, la riqueza de la obra literaria radica en que a la vez que se gesta en los mismos motivos, reiterando la pertenencia a una misma especie, también se plasma siempre en formas diferentes como seña de distinción entre los seres humanos.

Mircea Eliade se refiere así a esta cuestión:

En el detalle de su comportamiento consciente (...), el hombre (...) no conoce ningún acto que no haya sido planteado y vivido anteriormente por otro (...). Lo que él hace, ya se hizo. Su vida es la repetición ininterrumpida de gestos inaugurados por otros.

\section{La escuela como escenario para la acción}

Las prácticas de lectura y escritura sobre las que hace énfasis este documento son aquellas en las que la conversación y la escucha[6] constituyen los actos fundamentales para la construcción de sentido. Son prácticas de lectura que demandan del maestro el acto pedagógico de la mediación. Esto implica el hecho de que el maestro, dentro de la pluralidad y la contingencia de los signos arrojados por las historias de un libro y las representaciones que sus alumnos hacen, posibilita un escenario para su encuentro e intercambio. En este intercambio se reconocen como participantes de la conversación las narraciones, las opiniones y los argumentos particulares manifestados a través de la palabra, de los gestos o del silencio. Es decir, aquello que se dice y la manera en que se dice es, además, plural y contingente; no corresponde siempre a una secuencia lógica, también se debe tener en cuenta como elemento constitutivo de los diálogos cotidianos.

El acto pedagógico de la mediación se configura como acto, como acción — para ponerlo en términos de la filósofa alemana Hannah Arendt-, en la medida en que se encuentre acompañado de la reflexión y del discurso[7]. La acción de una práctica de promoción de lectura incorpora en su planeación y desarrollo la reflexión constante del mediador acerca de las representaciones que se tienen sobre la lectura, sobre la escritura, sobre los lectores y sobre sí mismo, en interacción con las representaciones e imaginarios que los otros hacen y 
manifiestan sobre los mismos u otros aspectos de carácter universal. Los espacios y las lecturas que se proponen a una comunidad de lectores están compuestos por esta carga significativa y tendrían que propiciar la transformación y creación de otras significaciones.

Niños, niñas y jóvenes necesitan espacios en la escuela que den valor a sus narraciones de vida como soporte de sus aprendizajes. Necesitan una escuela en la que su palabra tenga sentido, y en la que, a la par que se les exige su atención y su disposición hacia los saberes impartidos, puedan percatarse de cómo sus maestros abren un espacio para que sus acontecimientos habiten la cotidianidad escolar. Una escuela como la colombiana, en la que la mayoría de sus estudiantes sufren las consecuencias de la guerra y la crisis social, no puede darles la espalda a los miedos, al dolor y a la agresividad que portan los sujetos que todos los días asisten a los centros escolares. Tampoco puede abordar estas cargas identitarias y discursivas de manera metafórica, con iniciativas que en vez de invitar a la exteriorización solapen la consigna de que «a la escuela y al trabajo no se lleva la vida privada». No se trata solo de que la escuela cree espacios artificiales de tranquilidad y felicidad (en donde se ofrezcan desayunos, tecnologías, bellas edificaciones), o de disciplina y autoridad para reprimir las manifestaciones violentas. Se trata, también en el caso de la escuela, de que su cuerpo esté dotado de ideas, las ideas de todos, las historias de todos, por más duras que sean (Roa, P. y Castrillón, S. 2012, pp. 182).

De ninguna manera se espera que este sea un llamado a regodearse en el dolor o hacer de la experiencia pedagógica una procesión de testimonios trágicos para lamentarse. No privilegiamos el dolor y el drama por encima de otras manifestaciones de la vida, de las que, por supuesto - y esto es fundamental-, también la literatura se ocupa. En el acto pedagógico de la mediación, el maestro cuenta con la oportunidad y la responsabilidad de que con la lectura de la literatura se tome distancia frente a la tragedia, se la interpele, se la cuestione y se logre trascender la imagen trágica.

Así como sucede con la alegría y la belleza — sobre las cuales no se podrían establecer estrategias de receptividad edulcoradas en las que se perciba la felicidad como un fin en sí mismo-, lo doloroso por sí solo carece de significado y únicamente convoca a la piedad, a la indiferencia o a la resistencia. El dolor y las diversas emociones a las que se enfrentan los sujetos necesitan un reconocimiento en el ámbito público y también medios para poder ser expresados. Theodor Adorno (1966), al hablar del dolor y de su reconocimiento por parte de la educación, señala: 
La persona dura consigo misma se arroga el derecho de ser dura también con los demás, y se venga en ellos del dolor cuyas emociones no puede manifestar, que debe reprimir. Ha llegado el momento de hacer consciente este mecanismo y de promover una educación que ya no premie como antes el dolor y la capacidad de soportar los dolores. Con otras palabras, la educación debería tomar en serio una idea que de ningún modo es extraña a la filosofía: la angustia no debe reprimirse. Cuando la angustia no es reprimida, cuando el individuo se permite tener realmente tanta angustia como esta realidad merece, entonces desaparecerá probablemente gran parte del efecto destructor de la angustia inconsciente y desviada.

\section{Conclusiones y posibilidades}

Dentro de las anteriores consideraciones, el contexto colombiano sugiere que han sido pocas las posibilidades para el diálogo entre generaciones, grupos étnicos, clases sociales, coterráneos... A la vez, este contexto debería sugerir la urgencia de acciones que se encaminen a un restablecimiento del decir, del contar, del trasmitir y de hacer memoria de los tiempos que corren. Para ello, las mediaciones pedagógicas y culturales que involucran la lectura y la escritura son fundamentales.

Una de las satisfacciones que obtuvimos en el desarrollo de esta iniciativa de trabajo fue conocer por medio de los relatos de los maestros las particularidades de la vida en la escuela colombiana. Pudimos acercarnos -gracias a la voz que les dieron sus maestros en los espacios de formación- a las experiencias de muchos niños, niñas y jóvenes. Aunque en estos encuentros y seminarios solo participaron maestros y maestras, las palabras y las expresiones vitales de muchos otros tuvieron cabida a través de ellos. Junto con los maestros tratamos de tomar conciencia sobre la manera en que volvía a cobrar vigencia, vida y sentido la experiencia de los personajes de las historias leídas, la de los estudiantes que evocábamos a partir de ellas, y de otorgarle a esa experiencia un lugar destacado. En el caso de la lectura de los testimonios reales de víctimas de la violencia, procuramos reflexionar sobre la manera en la que, al leerlos, volvían al presente y mediante la palabra y la escucha tenían otra vez un lugar en el mundo.

Con relación al encuentro con cerca de quinientos niños, niñas y jóvenes en diferentes situaciones de vulnerabilidad y victimización, en estas conclusiones encontramos importante resaltar el hecho de que fueron determinantes, tanto en lo concerniente a la práctica como a la exploración y reflexión teóricas, cada uno de 
sus aportes en las sesiones de lectura. Cabe recordar que esos aportes nunca fueron medidos de forma exclusiva desde las intervenciones explícitas y orales, o en relación con su aprobación y participación «juiciosa» en los grupos de lectura, sino entendidos desde la generosidad de permitirnos participar de su cotidianidad y de su palabra, la disposición a la escucha y el pacto de asombro que conservan con las historias y la literatura.

Cuando nos cuestionábamos de manera crítica sobre el sentido de nuestro trabajo en estas comunidades, descubrimos que, a pesar de las experiencias dolorosas e injustas que les han tocado en suerte, los niños, las niñas y los jóvenes portan consigo la esperanza en la transformación del mundo, la noción sobre la importancia que tienen aquellos otros que los rodean y la necesidad imperiosa de construir y relatar sus historias. Así, nuestro trabajo tuvo como objetivo propiciar espacios para su visibilización significativa a partir de las prácticas de promoción de lectura y comunicar a la comunidad en general -sobre todo a la educativa- los hallazgos y reflexiones producto de esta experiencia.

\section{De los maestros y su formación}

Hablar de la transformación de las prácticas pedagógicas en una país como Colombia requiere situarse, antes que en el terreno de la técnica y de las estrategias metodológicas, en el plano de la reflexión, el estudio y el análisis crítico de esas prácticas.

Señalamos la urgente necesidad de que al momento de la toma de decisiones sobre las políticas educativas - tanto en la administración como en el ámbito de la escuela- se asuma de manera colectiva una postura crítica y vital acerca de la sociedad en la que crecen niñas, niños y jóvenes y sobre el papel que juegan en su formación el arte — dentro de él la literatura-, pero también la filosofía y las ciencias humanas.

Los maestros deben tener a su alcance las posibilidades para oponer resistencia a los hechos que transcurren fuera de la escuela y que la afectan, aunque es verdad que no son los maestros quienes pueden cambiar las realidades particulares e inmediatas que vive cada niña, niño o joven (certeza que, por lo general, se manifiesta en una profunda frustración o en el escepticismo de los maestros). 
Pensar en una resistencia pedagógica es considerar la capacidad que tienen los maestros de brindar las condiciones para que sus estudiantes — por medio del conocimiento, la imaginación, el lenguaje y una cotidianidad acogedora- puedan reflexionar, interpretar e interpelar lo que les pasa, comprender y resignificar la manera en la que se les presenta la realidad. Es decir, aplicar una resistencia pedagógica para que niños, niñas y jóvenes puedan resguardarse e inaugurar — de la mano de los aprendizajes vitales y científicos - una relación con el mundo en la que prime la certeza sobre las posibilidades de transformación y de ser sujetos activos de un presente y de un futuro propios. Enseñar sería así mostrar el mundo y acompañar el descubrimiento y la transformación que de él hacen los recién llegados, usando un término de la filósofa Hannah Arendt (1993).

Lo anterior significaría que la formación de maestros debe priorizar la reflexión permanente sobre estas cuestiones; debe ser una formación que contemple su palabra y su experiencia en consonancia con el flujo de acontecimientos externos que irrumpen en la escuela. La creación de espacios en los que los maestros lean, escriban, dialoguen y construyan conocimiento sobre su quehacer es un paso adelante para que la escuela colombiana reivindique su papel como lugar de la posibilidad y la acogida.

\section{Referencias bibliográficas}

Adorno, T. (1966). La educación después de Auschwitz. Conferencia emitida en Radio Hesse. Recuperado de https://www.equintanilla.com/documentos/articulo_adorno.pdf

Arendt, H. (1993). La condición humana. Barcelona: Paidós.

Asololectura. (12 de octubre de 2007). Clubes de lectores: una propuesta de promoción y reflexión. Clubes de lectura. Recuperado de http://clubesdelectura.blogspot.com/2007/10/introduccin.html

Badiou, A. (2004). La ética. Barcelona: Herder.

Bárcena, F. (2004). El delirio de las palabras. Barcelona: Herder.

Bruneteau, B. (2006). El siglo de los genocidios. Madrid: Alianza.

Duch, L. (2004). Estaciones del laberinto. Barcelona: Herder. 
Gordimer, N. (2004). Escribir y ser. En Discursos Premios Nobel (Tomo 3). Bogotá: Común Presencia Editores.

Jelin, E. (2002). Los trabajos de la memoria. Madrid/ Buenos Aires: Siglo XXI.

Mate, R. (2003). Memoria de Auschwitz: actualidad moral y politica. Barcelona: Trotta.

Mèlich, J. C. (2002). Filosofía de la finitud. Barcelona: Herder.

Mircea, E. (2009). El mito del eterno retorno: arquetipo y repetición. AlianzaEmecé.

Roa, P., Castrillón, S. (2012). Narrar la violencia. Docta, 10(8), 175-182.

Recuperado de http://apcweb.com.ar/wpcontent/uploads/2014/10/Docta08-WEB.pdf

Tafalla, M. (2003). Theodor W. Adorno: una filosofía de la memoria. Barcelona: Herder.

\section{Notas}

[1] Según Hannah Arendt, «el discurso corresponde al hecho de la distinción y es la realización de la condición humana de la pluralidad, es decir, de vivir como ser distinto y único ente iguales (1993)».

[2] Nos permitimos tomar como derrotero fundamental de este documento el imperativo categórico de Theodor W. Adorno, que —-después de la Segunda Guerra Mundial- establece como exigencia de la educación evitar que Auschwitz se repita. Dicho derrotero de reflexión, con el que Asolectura ha planteado sus propuestas de trabajo durante los últimos tres años - sobre todo en lo concerniente al proyecto IBBY para el trabajo de mediación de lectura en poblaciones de niños, niñas y jóvenes en situación de crisis-, se toma dentro del contexto colombiano guardadas todas las proporciones. Si bien nos permite establecer un espejo de confrontación importante y un marco conceptual definitivo, no tiene ningún interés -y en esto ponemos especial énfasis- hacer una comparación entre ambas tragedias sobre las cuales nuestro alcance de estudio se ve limitado, además de no ser del interés de este documento. Sin embargo, con respecto al tema, nos acogemos a la tesis de Bernard Bruneteau (2006) expuesta en el libro El siglo de los genocidios, en el que señala que «comparar es 
simplemente intentar dar un sentido histórico a los acontecimientos a menudo independientes entre sí, resaltando sus diferencias y similitudes sin pretender decir que lo uno "equivale" a lo otro». Con respecto al imperativo categórico adorniano, se recomienda explorar su bibliografía, y como texto de referencia importante, su conferencia de 1966 titulada «La educación después de Auschwitz».

[3] Según Alain Badiou (2004), subordinar la idea de víctima al cuerpo que sufre, despojando al cuerpo de toda idea, funda la «esclavitud moderna»:

La injusticia es un cuerpo sufriente visible, es el espectáculo de las personas sometidas a suplicios, muertos de hambre, heridos, torturados, y es cierto que en la gran muerte del espectáculo hay un sentimiento de la piedad. Pero si la víctima es el espectáculo del sufrimiento, podemos decir que la cuestión de la justicia es solamente la cuestión del cuerpo, la cuestión del cuerpo sufriente (...) cuerpo visible y deviene cada vez más un cuerpo espectáculo, ya que nuestra época transforma cada vez más el sufrimiento en espectáculo, no solamente el espectáculo imaginario, en el cine de la tortura y la violencia, pero también es documento bruto, que nos muestra el cuerpo espectáculo, el cuerpo sufriente, en donde la humanidad es reconducida a la anormalidad.

[4] La referencia a esta experiencia y observación concretas se amplía en el documento de investigación del Programa Clubes de Lectores para el período 2009.

[5] Las ideas planteadas en este capítulo están basadas en las propuestas teóricas de los profesores y filósofos de la educación Joan-Carles Mèlich (2002) y Fernando Bárcena (2004). De la misma manera fue fundamental el acercamiento a Elizabeth Jelin (2002), cuyas reflexiones sobre la memoria en el contexto de las dictaduras de los países del Cono Sur permitieron hacernos a una idea más concreta del significado de la memoria en situaciones de violencia como las colombianas.

[6] Se recomienda para ampliar el concepto de la escucha como acto pedagógico revisar el trabajo realizado por la profesora argentina Cecilia Bajour.

Hacemos referencia a este concepto para sugerir la exploración de las propuestas de Hannah Arendt, en especial en el texto La condición humana. Las obras de los filósofos Fernando Bárcena y Joan-Carles Mèlich son excelentes aproximaciones a la pedagogía de esta autora.

\section{Notas del autor}


El presente artículo es producto de un proyecto financiado con el Fondo de IBBY para Niños en Crisis, y realizado por Asolectura -Colombia-, con la colaboración del Banco del Libro -Venezuela- en 2009. Ha sido revisado y actualizado para su publicación en esta oportunidad, mayo 2021.

\section{Nota del editor}

El presente manuscrito fue aprobado para su publicación por Cristina Deberti.

La corrección de estilo del presente texto fue realizada por Irene Busakre en el marco del convenio celebrado entre la FHCE (Tecnicatura Universitaria en Corrección de Estilo-Facultad de Humanidades y Ciencias de la Educación) y la FIC (Facultad de Información y Comunicación).

\section{Nota de contribución autoral}

Las autoras elaboraron en partes iguales el presente manuscrito. 